\title{
Mapping Pupil's Learning Progression Using Hand Manipulatives and Touch Screen Applications: Implications to Post-COVID-19 New Normal
}

\author{
Gamaliel Gonzales \\ Educational Research and Resource Center, Cebu Technological University, Cebu, Philippines \\ Correspondence should be addressed to Gamaliel Gonzales; gamaliel.gonzales@ctu.edu.ph
}

Received 24 August 2021; Accepted 8 February 2022; Published 7 March 2022

Academic Editor: Ehsan Namaziandost

Copyright ( 2022 Gamaliel Gonzales. This is an open access article distributed under the Creative Commons Attribution License, which permits unrestricted use, distribution, and reproduction in any medium, provided the original work is properly cited.

\begin{abstract}
The study investigates the shifts in pupils' learning progression levels while they learn fractions using hand manipulatives and touch screen applications. A total of 10 children paired with preservice teachers participated in a 12 -week learning design. This was performed during the disruptions of the academic year due to the COVID-19 pandemic. The study uses the convergent mixed methods design to document qualitative and quantitative data. The method enables the researcher to compare, relate, and merge results. The author develops a microscoring tool to help the preservice teachers analyze observed learning progressions. The theoretical underpinning was based on a constructivist environment while learning mathematics. Results documented evidence of shifts and recursions in children's learning progressions along with the Pirie-Kieren model while interacting with hand manipulatives and touch screen applications. The quantitative and thematic analyses revealed three different shifts in pupils' learning. The study suggests that an open-ended number of tasks at varying levels of difficulty led the pupils to refine their understanding of the concept image resulting in progression shifts in learning. With the interconnectedness of the findings, it is proposed that design features in mathematics apps paired with manipulative kits be investigated on a large population. Implications for delivery modes and policy directions in post-COVID-19 new normal are presented.
\end{abstract}

\section{Introduction}

To control the outbreak of the COVID-19 virus, the delivery of instruction has changed from in-person to remote teaching [1], increasing inequalities and affecting the most vulnerable school-aged children [2]. The shift of the educational system has subsequently accelerated the usage of emerging digital gadgets dividing simultaneously between people with versus without access to the technologies [3]. This disparity became evident when rich countries readily adopted complete online learning. At the same time, developing countries, such as the Philippines, have shifted to modular distance learning in their public school system due to some challenges in online infrastructure. However, the literature showed that equalizing learning profiles across different countries requires more than closing the rich-poor gaps but an equal learning progression for all [4]. Akmal and
Pritchett [4] added that even with equity goals of schooling and learning, children are still far from mastering basic mathematics by the age of 12 or 13 .

Learning the concepts of mathematics is a robust process. The learners' mathematical knowledge advances by developing numerical information through a concrete, procedural, symbolic, and formal understanding [5-7]. Pirie and Kieren [7] argued that learning has to be an effective action and that mathematical understanding expands outward as they progress on a learning progression model. Learning progression is the term used to refer to the noticeable changes in mathematics learning. For example, Watts et al. [8] revealed that children's learning patterns could be evident if given a variety rendering of tasks at varying levels of difficulty, resulting in an observed progressive pattern in the Pirie-Kieren theory. The model perceives children's understanding as a dynamic, leveled but 
nonlinear, recursive process and details eight potential levels of actions for mathematical understanding. Each level of understanding is contained with subsequent levels and is dependent on the processes within and further, is constrained by those without [9]. Because of its emphasis on observing the whole process of gaining understanding, the Pirie-Kieren theory has the potential to be a helpful tool to trace a learner's growth of understanding of fractions using manipulatives or touch screen applications.

Primary school teachers need to be innovative in utilizing learning tools to enhance mathematics teaching and learning $[5,10]$. Teaching with manipulatives is one of its best examples. Manipulatives are objects utilized in classrooms to make ideas in mathematics tangible. Manipulatives are both concrete and virtual objects that can represent and give meaning to abstract mathematical concepts [11]. In the past 20 years, there has been continuing experimentation, virtual applications, and software trying to invade the century-long concrete hand manipulatives in teaching mathematics. For example, a tablet multitouch app can elicit a broad range of number sense abilities among preschoolers [12]. However, Doias [13] revealed that the combination of both hand and virtual manipulatives effectively increases the students' assessment scores and leads to positive changes in the attitude toward learning mathematical concepts. The variety of hand and touch screen manipulatives can enhance children's psychomotor and cognitive development.

Documenting the learning progressions shifts of the pupils as they are exposed to hand and touch screen manipulatives is still unexplored. The study of Watts et al. [8] reported progression shifts of the children's learning using mathematics apps touch screen application. However, unhealthy ways of using touch screen applications keep our school-aged children as digitally disadvantaged learners [14]. The environment of techno-microsystem produces consequences of the use of technology among children. On the other hand, several research studies have indicated that hand manipulatives effectively develop children's conceptual and practical knowledge in mathematics $[11,15]$. A systematic review of studies on the effects of manipulatives on mathematically challenged children revealed that interventions with manipulatives are promising [16]. This paper provides specific interventions to mix the touch screen apps with tangible hand manipulatives to minimize digital disadvantages on children. The study focused on the competencies of the basic operations of fractions among pupils in the age range of 8-10 years old. The learning progression model in the Pirie-Kieren theory [17] was used to trace the analytical and cognitive discovery of the pupils while using the manipulatives.

\section{Pirie-Kieren Theory}

The Pirie-Kieren theory is a nested description of a learner's growth of understanding classified on eight layers of measures from primitive knowing to inventizing (see Figure 1). The notion is that the nature of understanding the concepts in mathematics is getting more general and abstract as the learning moves continuously

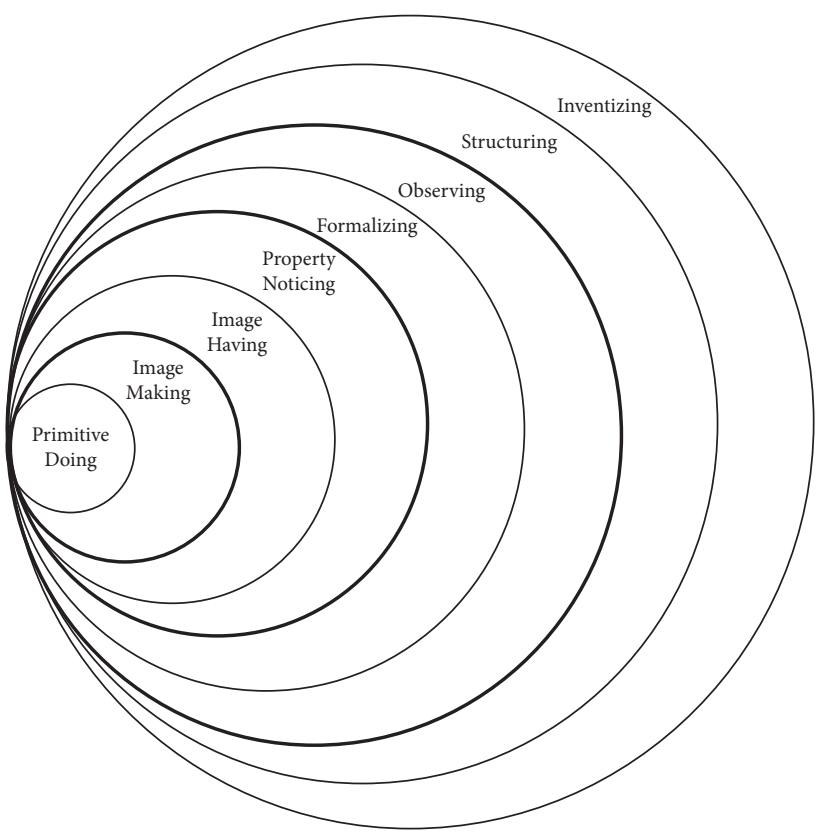

FIgUre 1: Pirie-Kieren theory of mathematical understanding [17].

through the layers of knowing. Because mathematical understanding can be distinguished as leveled across stages, this motion is not necessarily linear but may depict recursive looping patterns describing the unlearning and relearning of concepts [17].

Figure 1 presents the diagrammatic circles illustrating the rendition of the Pirie and Kieren theory. The recursive phenomenon is observed when mathematical thinking moves between levels of sophistication. Granting it is beyond the range to fully delineate the idea with the exact data of mathematical understanding of the pupils, Pirie and Kieren [9] highlighted that the model is effective in comprehending the episode of pupils' behavior with a specific topic such as fractions and its operations. This paper employs a rubric in observing the complex leveled phenomenon with videorecorded files of the learning activities to allow reobservation and validation of recursions.

The first level occurs when the learner begins to picture concepts from "primitive doing." This level may involve figures, objects, or graphics as aids of learning and pattern recognition. The term "primitive" does not refer to low-level mathematics but is a starting place for developing specific mathematical understanding [17]. The first recursion on primitive doing occurs when the learner begins to form images out of the task given. The effective actions here involve the second level of "image-making." At this level, the learners are involved in specific thinking that will help them develop an image of the concept that they are trying to explore [18]. Pictures of the ideas established at this level are not separated from the actions specifically produced by this cognition. From the point of view of mathematical understanding, the third level, "image having," frees a pupil's mathematics from the necessity to take particular actions as a guide to understand the concept. The image having is the first level of abstraction, but it is critical to note that the 
learner makes this abstraction by recursively building on images based on action. In order to improve the understanding, these images cannot be imposed from the outside since knowing has to be an effective action. The recursions do not stop here. The images formed are examined for specific and relevant properties. These actions involve noticing distinctions, combinations, or connections between images. The fourth level, "property noticing," is considered the outermost part of unself-conscious knowing. The word outer refers to imply levels of understanding wrap around each other, as illustrated in Figure 1, and contain, indeed require, the possibility of access to all previous levels. Levels of understanding do not equate with higher or lower levels of mathematics.

The fifth level, "formalizing," denotes higher-order thinking skills that can sequentially attain from the previous levels. The pupils can produce a general statement about the idea by examining the images from image forming, the image having, and understanding the underlying properties in the stage of property noticing [9]. The construction of formal definition in mathematics is developed from algorithms of the topic [19]. The pupils need help escalating their conceptions with fractions to formally connect their understanding of fractions using manipulatives to procedural knowledge [13]. The sixth level, the "observing," will just come close with formalizing. In this level, the pupils observe the meaning they have organized and formalized from observations. They replicate and organize formal action and prompt coordination as a new understanding leading to a theorem [7].

The last outermost levels (seventh and eighth) are "structuring" and "inventizing." Structuring occurs when a pupil attempts to reason out from formal observations as a theory [7]. The level means that the child is now collecting inter-relatedness of theorems and verifying the statements through a reasonable argument. In this stage, the pupils' mind will filter physical chunks of information from imagemaking or property noticing and make partitions of higher concepts than just formalizing. Inventizing is the sealant stage. The pupils reach a structured understanding which will enable them to formulate new queries from which an entirely new concept may begin [9].

\section{Research Questions}

The overarching hypothetical viewpoint of this paper was how the use of hand manipulatives and touch screen applications in teaching fractions produce incremental shifts in pupils' learning progression. Uncovering a deeper understanding of how the pupils progress in their learning could lead to policy directions on using hand manipulatives and touch screen applications in teaching fractions. Thus, the following research questions were posed: What were the different learning progression shifts of the pupils while using the hand manipulatives and touch-screen manipulative apps? What were the pupils' experiences while learning fractions in hand manipulatives and touch-screen manipulative apps?

\section{Methods Used}

This study employed the convergent mixed methods design following a contemporary collection of quantitative/qualitative data and merging the results to interpret or explain the convergence or divergence of the findings [20-22]. This design aims to get corresponding information on similar themes and comprehend the complementary results of the quantitative and qualitative analyses. The quantitative data include the pretest and post-test scores and graphical information derived from the learning progression across the Pirie-Kieren theory. The qualitative data consist of the thematic studies based on the data gathered in semistructured interviews, the anecdotal records of the preservice teachers, and the field notes observed when deciding on the progression shifts in the Pirie-Kieren theory. Orientation with the app was made to ensure that the pedagogical skills of the preservice teachers are aligned with the technological knowledge that they wish to employ [23]. A checklist (see Table 1) was developed to carefully track learning progression with descriptions specific to learning concepts on fractions and learning expectations. Wilkins and Norton [24] outlined a learning progression scheme for fractions as (1) "part-whole scheme" PWS), (2) "measurement scheme for unit concepts" (3) "measurement scheme for proper fractions" (MSPF), and (4) "generalized measurement scheme for fractions" (GMSF).

The basis for validity and reliability of the developed micro-scoring, Creswell [21] recommends using data triangulation on a mixed-method design. The data triangulation was achieved by examining and reviewing the video vignettes several times, which was conducted by the researcher and the cooperating preservice mathematics teachers.

4.1. Participants and Procedures. Ten pupils and ten preservice mathematics teachers participated in the study. The recruitment was based on the availability of a preservice teacher and a primary grader in one household since the data gathering was performed during the general community quarantine (GCQ) due to the COVID-19 pandemic. Nine pairs of pupil-preservice teachers were at Danao City, while one pair were at Compostela in the province of Cebu, Philippines. The age ranges of the pupils were 8-10 years old with 3 or $30 \%$ in Grade 2, 5 or $50 \%$ in Grade 3, and 2 or $20 \%$ in Grade 4. The selection is based on Jean Piaget's concrete operational stage, which states that the effectiveness of manipulatives is completed by the age of ten or eleven years and that these are no longer needed after that age [25]. All activities followed the protocols of the local authorities and interagency task force (IATF) in the Philippines during the implementation of the research. The orientation and training of the preservice teachers were performed online using the flexible learning platform of Cebu Technological University, Cebu, Philippines. The participants were provided with a mathematical kit for teaching fractions and tablets with applications in manipulatives. The mathematical kit for teaching fractions is a utility model registered under 
TABLE 1: Checklist on learning progression in the operations of fractions based on the Pirie-Kieren theory Approach.

\begin{tabular}{|c|c|c|}
\hline Level [17] & $\begin{array}{l}\text { Description } \\
{[24]}\end{array}$ & Learning Progression Expectations about Fractions \\
\hline $\begin{array}{l}1 \\
\text { Doing }\end{array}$ & PWS 1 & $\begin{array}{l}\text { The child knows moving hand and touch screen manipulatives but does not count aloud the concept of } \\
\text { fractions to match with the objects. }\end{array}$ \\
\hline Image-making & PWS 2 & $\begin{array}{l}\text { The child says numbers as a part of the whole but does with exact correspondence of the uttered } \\
\text { concepts of fractions and the manipulatives. }\end{array}$ \\
\hline $\begin{array}{l}3 \\
\text { Image having }\end{array}$ & MSUF 1 & $\begin{array}{l}\text { For at least five objects in hand and touch screen manipulatives, the child says the exact values and } \\
\text { matches each spoken fraction with the objects. }\end{array}$ \\
\hline $\begin{array}{l}4 \\
\text { Property } \\
\text { noticing }\end{array}$ & MSUF 2 & $\begin{array}{l}\text { The child has developed an understanding of the addition and subtraction of similar fractions using the } \\
\text { hand and touch screen manipulatives. }\end{array}$ \\
\hline $\begin{array}{l}5 \\
\text { Formalizing }\end{array}$ & MSPF 1 & $\begin{array}{l}\text { The child has understood the multiplication and division of similar fractions using the hand and touch } \\
\text { screen manipulatives. }\end{array}$ \\
\hline Observing & MSPF 2 & $\begin{array}{c}\text { The child has developed an understanding of the addition and subtraction of dissimilar fractions using } \\
\text { hand and touch screen manipulatives. }\end{array}$ \\
\hline $\begin{array}{l}7 \\
\text { Structuring }\end{array}$ & GMSF 1 & $\begin{array}{l}\text { The child has developed an understanding of multiplication and division of dissimilar fractions using } \\
\text { the hand and touch screen manipulatives. }\end{array}$ \\
\hline $\begin{array}{l}8 \\
\text { Inventing }\end{array}$ & GMSF 2 & $\begin{array}{l}\text { The child can explain the operations of fractions and provide more examples using the hand and touch } \\
\text { screen manipulatives. }\end{array}$ \\
\hline
\end{tabular}

the intellectual property office of the Philippines (IPOHL) comprising of a plurality of polygonal tiles, which will help the teachers explain abstract concepts with concrete examples, especially in operations fractions [26]. The common sense media (CSM) application was used as the touch screen virtual manipulatives. The app of CSM is a touch screen manipulative that will help children visually understand the relationships among percentages, fractions, and decimals. Pretests and post-tests were given before and after the learning tasks. The learning tasks were carried out in twelve weeks, spanning from June 1, 2020 to August 23, 2020. Parents/guardians testified on children's use of touch-screen devices (TSDs) at home. All have access to TSDs at home, with $13 \%$ having more than five available TSDs, $13 \%$ had between three and four, and $75 \%$ had between one to two. Thirty percent of children used the TSDs every day, $50 \%$ used it 4-5 days per week, and 20\% used it three days per week.

One way of pinning the learning progression shifts is through video recording [8]. The researchers developed checklists (see Table 1) that serve as micro-scoring tools to trace the Pirie-Kieren theory's progression shifts. The term "trace" was used by Adesina, Stone, Batmaz, and Jones [27] to track the learning with video recordings. The student-teacher counterparts took pictures and recorded the videos covering the activities of the pupils while doing the learning activities. The video recordings will serve as trace path history and will verify the direct observations conducted by the student teachers.

4.2. Data Analysis. In the context of analyzing quantitative and qualitative data, four sources are used to determine changes in pupils' learning: the scores in prepost assessment, the learning progression pattern observed per week, the anecdotal records performed by the preservice teachers, and the transcripts of the semi-structured interviews. The results were collated with three analytical techniques: visual, statistical, and thematic analyses. Different analytical methods are usually used in a convergent mixed methods design since it supports parallelism in answering interdependent research questions and allow researchers to harmonize quantitative and qualitative data [20,22]. Data that complement each other are good at capturing the phenomenon, especially if we are bound to pin down the child's learning progression.

In the visual analysis, the cooperating preservice teachers examined the learning progression levels using a checklist as shown in Table 1. These learning progression reports were presented as sequence charts for the graphical analysis. Another statistical analysis included was the $t$-test for correlated samples to determine a significant improvement in the pretest and post-test scores. The hypothesis test results were compared if it conforms to the observed learning progression levels and the themes drawn from the experiences of the pupil respondents. Transcripts of the semistructured interviews, video recording, and FGD were analyzed using NVivo Pro software. The NVivo software supports qualitative and mixed methods research by helping researchers organize, analyze and find insights in unstructured interviews and multimedia information.

\section{Results}

The results include each learning sequence with the pupil's interview experience and sequence chart analysis. The data are presented so that small shifts in children's learning progressions are visible. The student-teacher counterparts deliberately performed these observations using the observation checklists and retraced the correctness of progression through the video vignettes gathered during the learning activities. To elaborate qualitative discussions, the researcher examined the videos and interview transcripts. It was made sure that getting closer to elaborate discussions was made without losing the context of the observations performed by the student teachers, as suggested by Blikstad-Balas [28].

The results revealed three different types of learning progression shifts; (1) the irregular recursions in the model, 

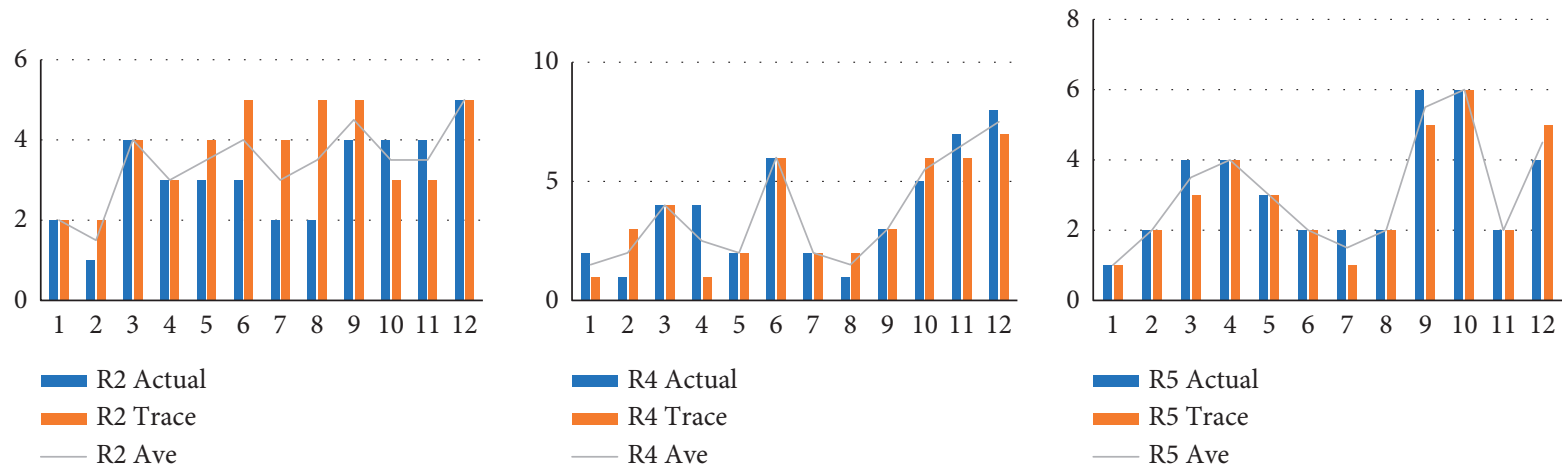

Figure 2: Chart of actual, trace, and average progressions of the pupils identified as irregular shifters.

(2) slow incremental shifts, and (3) regular incremental progressions. Each of the identified learning progressions is presented with sample interviews to entice more discussions. The charting of progression levels includes the actual observations of the preservice teachers on the pupil they are supervising, the trace extracted from the video vignettes, and the average of the actual observation and the trace.

5.1. Irregular Shifts in Learning. The sequence chart revealed a generally increasing recursion on the nested description of the understanding of the Pirie-Kieren theory in a 12-week learning design. It can be gleaned in Figure 2 that respondent 5 showed more retractions in the learning progression and is followed by respondent four and respondent 2 .

With the aid of a micro-scoring tool, actual observation on the progressions using field notes and the "trace" on video vignettes were performed. Results revealed discontinuous jumps on respondents 2, 4, and 5. Wilensky [29] stated that discontinuous jumps occur when the movement of learners along the specified progression levels is not smooth, which can be associated with specific ways of understanding. Crosschecking interviews revealed the following realizations.

"I am happy because I could learn new things; this is my first time learning fractions with a manipulative kit and fraction apps on a tablet. I could learn on my own even without our teachers. The problem is that I am not used to learning independently, and sometimes I learn nothing (respondent 5). I know to do basic operations in fractions with different denominators. However, I quickly forget the idea when I do it again by myself. I need somebody to guide me or will watch the tutorial again and again (respondent 4)."

The observed recursions and the qualitative data support that some children are still dependent learners and that more learning and unlearning happened when no one is there to guide the learning process. These were the main reasons why the learning recursed back and forth along with the Pirie-Kieren model for respondents 2, 4, and 5. This result supports the findings of Mendiburo et al. [30]; which states that teachers need to spend considerable time helping the students learn, especially when introducing new visual tools such as manipulatives in teaching fractions and touch screen apps. An important observation is that the pupils mentioned above are quick at understanding the concepts at first glance but are also quick to forget these concepts after the learning sessions. These learners need helping affordances that are accessible to the children who progressed between the preand post-assessments. Crosschecking interviews revealed that they would turn their attention to other things and stop learning when no one is there to guide them.

Looking at the learning progression of respondent 4 , it went as high as Step 6 on the sixth week but went down to Step 1 in week 8 . A personal interview with the preservice teacher supervising the child revealed that the family had some problems related to COVID-19 and the quarantine. Crosschecking with the video vignettes during these days showed that the child could not focus and did not answer the learning activities. Therefore, it cannot be denied that personal family problems affect learning and even changes attitude toward learning. Another factor is the unlearning effect when the session is performed. Among the irregular shifters observed, Pupil 2 is the one that never reached the observing level in the Pirie-Kieren model. Pupil 2 is a shy type of child and is described as a dependent learner. The mathematics performance of pupil 2 .

5.2. Small Incremental Shifts. Other notable results in the sequence chart are the observed small incremental shifts (SIS) as depicted by pupils 3, 6, 7, and 8 (see Figure 3). SIS comprised $40 \%$ of the respondents. Learning progressions can reveal the SIS in children's cognitive organization. Clements and Sarama [31] noted that SIS allows researchers to establish specific objectives for a particular pupil. Interview transcripts reveal that these pupils were having common experiences explaining SIS. For example, they felt like learning fractions is difficult for first-timers, but they play while learning as they understand its usage.

It is pretty tricky to use at first, but it is just like playing while solving problems if you get used to it. (respondent 3). It is hard because I am unfamiliar with manipulatives, but I discovered new ways of knowing fractions (respondent 6). Sometimes I get confused, but the good thing 

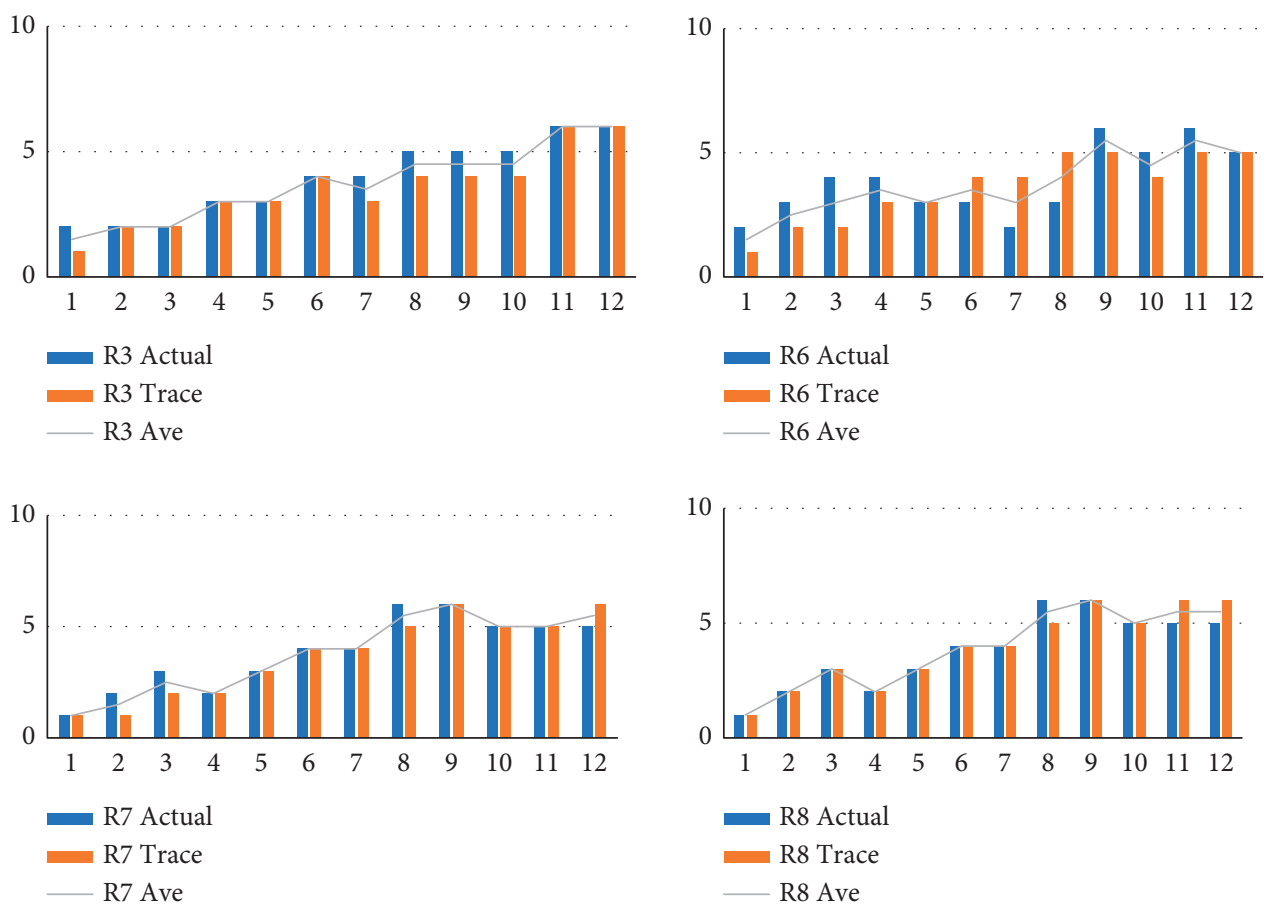

Figure 3: Chart of actual, trace, and average progressions of the pupils identified as small incremental shifters.
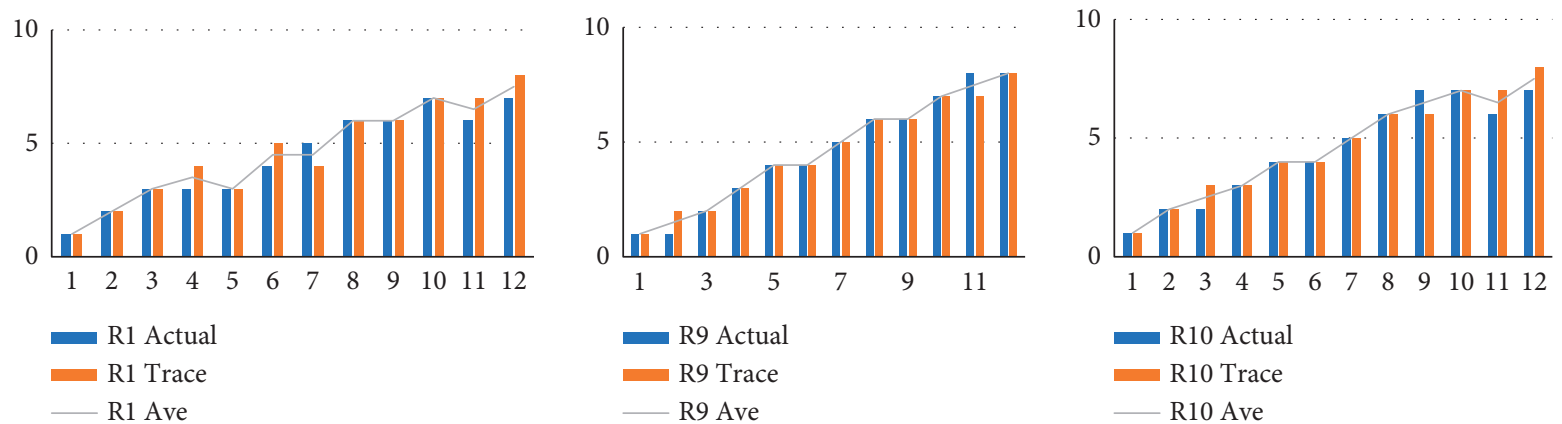

FIGURE 4: Chart of actual, trace, and average progressions of the pupils identified as regular shifters.

is that you can explore more according to your pace (respondent 7). I was not able to understand how to use the manipulative tiles not until I was given instructions on how to do it. From then, on I gradually visualize fractions and began to learn while playing (respondent 7).

5.3. Regular Progression Shifts. The pupils identified with regular progression shifts showed numerous shifts than their counterparts (see Figure 4). It is important to note that completing more tasks at varying levels of difficulty will allow the pupils to have more drills on a topic, leading to a more concrete understanding. The respondents with regular progression shifts are pupil numbers 1,9 , and 10 , with charts shown in Figure 4.

The average grade of regular progression shifters is 90 , a unit higher than the irregular and two units higher than the small incremental shifters. The good thing about the apps is that it allows differentiation of learners and that more capable pupils could go faster in the varying levels of task difficulties [8].

Learning with the app is just like playing a game. You go to different levels. Suppose you like easy tasks; you can; if you like challenging tasks, choose the level (respondent 1). Using both the app and the kit is nice. The learners must get used to using them. I recommend that teachers use this in school because it is gratifying (respondents 9 and 10).

5.4. Comparison between the App and the Kit. Fifty percent of the respondents preferred to learn fractions with the app, 30 percent favored the kit, and 20 percent chose to learn with the combination of the app and the kit. During the follow-up interview, pupils who are inclined to learn fractions with the app revealed that learning fractions were fun and challenging. 
The puzzle games in-app are so challenging. Although the hand manipulatives are more concrete, the app facilitates faster learning (respondent 1). I enjoyed learning fractions more using the app than the manipulatives. I could understand easily using the app because it will tell you directly if your answer is correct or wrong (respondents 2 and 6). You can play with an opponent also using the app. It is more challenging (respondents 4 and 10).

Among those who prefer to learn fractions with the kit, it is noteworthy that some revealed that it is a new way of learning fractions. This finding means that hand manipulatives are not introduced in their schools. It was also revealed that using the kit is a good way of cutting the pupil's time spent in video gaming. Although more prefer to learn with the app, when asked if they will recommend the kit, all respondents agree that the teachers must use hand manipulatives in schools. The respondents said

Using the kit is a new way of learning fractions. I enjoyed assembling the tiles (respondent 5). If I want to relax from playing video games, I will learn fractions using the kit (respondents 3 and 9).

The two pupil respondents suggested that the kit must be used together with the app. According to them, the hand manipulatives are good at discovering the actual partitions of fractions, while the app will complement the exercises and solutions. The kit is good at learning the basic knowledge about fractions, while the app will enhance the essential learning because of its ability to have more visualization effects.

It is excellent to see how the ideas in the app can be verified using actual manipulatives (respondent 7). The kit is very interesting, but it must be accompanied by the app (respondent 8).

\subsection{Pre-Post Comparison by Competencies in the Learning} Progression. Table 2 showed the paired $t$-test for the pretest and post-test scores of the pupil respondents in the six competencies of learning fractions. All except the first competency gave significant results at 0.05 alpha level. This finding means that the pupil respondents were already equipped with the basic knowledge in visual identification of fractions. This competency is the springboard from kindergarten mathematics. The pupils will only identify what shaded regions represent part of the whole. The significant improvement in all other competencies signifies that using the mathematical kit for teaching fractions and touch screen manipulatives in the app effectively improves the pupils' mathematical skills.

\section{Discussions}

This study hypothesized that examining shifts in pupils' learning progression levels as they interacted with manipulatives in the kit and apps could lead to a greater understanding of how those shifts related to children's learning.
The results revealed that we could document evidence of shifts in children's learning progressions. At the same time, they interact with manipulatives, indicating patterns in the pupil's activities related to the shifts in their learning progression levels. This learning supports the work of DuzenliGokalp and Sharma [32], which states that the relationship between the pupils' preference on utilizing representations of fractions leads to shifting on different levels of understanding. The different progression shifts documented from the results support the theoretical perspectives. The description of the development of learning is dynamic, nonlinear but leveled, and follows a particular recursive process [9]. The results suggest that the identified tasks at varying levels of difficulty led the pupils to refine their understanding and shape their concept image of ideas about fractions resulting in progression shifts in learning.

The result showing that pupils with family problems at home tend to go more recursive patterns in the learning progressions is supported with King et al. [33], which states that the most important support to learning pathways among children is the family functioning and support of parents. Children's pathways to academic and social competence also had particular attention in investigating the role of children's health and the distinction between activitylimiting conditions as a factor affecting learning [34]. Becker et al. [35] also affirmed that the near-universal closure of schools due to the COVID-19 pandemic affecting financial and health problems has led to remote learning difficulties among family members attending schools.

Learning progressions can reveal the small incremental shifts in children's cognitive structures. Clements and Sarama [31] note that examining this movement allows researchers to answer questions such as what new objectives should be established for a particular child and what developmental tasks would be appropriate for that child to achieve those objectives. For example, during the unstructured interview, one of the pupil respondents reveals that she is tempted to play other games in the app and tends to play those games when the preservice teacher facilitator is not around. The natural tendency is that the pupil is more inclined to use the app than the manipulatives in the kit. However, due to a regular engagement of the preservice teacher, a notable incremental shift was observed in this pupil respondent. Thus, an overall analysis of a child's incremental shifts in learning could aid an educator in understanding a child's learning needs. Mendiburo et al. [30] support the findings stating that teachers need to spend considerable time helping the students learn, especially when introducing new visual tools such as manipulatives in teaching fractions and touch screen apps.

The statistical and thematic analyses revealed incremental shifts in pupils' learning during their interactions with the manipulatives. The findings showed several examples of these types of shifts for individual pupils. For example, eight out of ten participants showed constant progression in the Pirie-Kieren recursion pattern and were observed to have significant improvements from the pretest scores to post-test scores. Although there are notable backward paths in the recursion of the two participants, the overall statistical test 
TABLe 2: Paired $t$-test of the pretest and post-test of the competencies of learning fractions.

\begin{tabular}{|c|c|c|c|c|c|c|}
\hline Competency & & Mean & Standard Deviation & $t$ statistic & $p$-value & Findings \\
\hline \multirow{2}{*}{ Visual identification of fractions } & Pretest & 7.80 & 4.158 & \multirow{2}{*}{2.042} & \multirow{2}{*}{$>0.05$} & \multirow{2}{*}{ Not significant } \\
\hline & Post-test & 9.50 & 0.972 & & & \\
\hline \multirow{2}{*}{ Visual representation of fractions } & Pretest & 8.50 & 3.375 & \multirow{2}{*}{1.831} & \multirow{2}{*}{$\leq 0.05$} & \multirow{2}{*}{ Significant } \\
\hline & Post-test & 9.90 & 0.316 & & & \\
\hline \multirow{2}{*}{ Addition and subtraction of similar fractions } & Pretest & 6.10 & 4.508 & \multirow{2}{*}{3.699} & \multirow{2}{*}{$\leq 0.05$} & \multirow{2}{*}{ Significant } \\
\hline & Post-test & 9.80 & 0.632 & & & \\
\hline \multirow{2}{*}{ Addition and subtraction of dissimilar fractions } & Pretest & 1.00 & 1.633 & \multirow{2}{*}{5.640} & \multirow{2}{*}{$\leq 0.05$} & \multirow{2}{*}{ Significant } \\
\hline & Post-test & 7.00 & 4.000 & & & \\
\hline \multirow{2}{*}{ Multiplication of fractions } & Pretest & 4.20 & 4.590 & \multirow{2}{*}{4.648} & \multirow{2}{*}{$\leq 0.05$} & \multirow{2}{*}{ Significant } \\
\hline & Post-test & 8.90 & 3.143 & & & \\
\hline \multirow{2}{*}{ Division of fractions } & Pretest & 4.40 & 4.575 & \multirow{2}{*}{4.046} & \multirow{2}{*}{$\leq 0.05$} & \multirow{2}{*}{ Significant } \\
\hline & Post-test & 8.50 & 3.064 & & & \\
\hline
\end{tabular}

supports a good and satisfying learning progression in the 12week time series data. Documenting these discontinuous jumps allowed us to trace each pupil's movement and learning progressions using the app and the kit. It would not have observed this continuum of growth without using a microscoring tool and an examination of every task every pupil completed throughout the learning sequences.

\section{Implications to Post-COVID-19 New Normal}

All pupils in the study recommended that manipulatives be part of the learning strategies in understanding the concepts of fractions. This finding is supported theoretically. According to the cognitive psychologist and educator Jerome Bruner [36], individuals learn by distinguishing symbols and shapes. Learners "remember a formula, a vivid detail that carries the meaning of an event" (p. 25). Acquisitive with symbolic notation is the first step in understanding mathematical concepts. As children absorb the given concept more profoundly, the layers of meaning will unfold, moving from concrete perceptions to abstract understanding of the concepts. This theory supports the need to use manipulatives in teaching fractions. The primary school graders need to channel their energy to something relevant to them. Hand manipulatives provide the children with opportunities to be actively involved in evocative learning experiences. If the learners become actively engaged in the process, they take ownership of what they have learned and transfer from concrete to abstract concepts by themselves [13, 37, 38].

Recent development in teaching has devised two types of manipulatives, the actual hand manipulatives and touch screen applications. In today's digital world, gadgets are communication devices that are basically intended to facilitate adults' essential functions. Children should be considered vulnerable to media overuse and addictive behaviors [39]. This paper concludes with intertwining discussions on the use of touch screen applications and concrete hand manipulatives with a balance. Therefore, lessening the children's exposure to digital media and open advocacies to improve the curricular design intended for primary schoolers' age group. As we approach the postCOVID-19 new normal, the education sector must consider these emerging challenges on over-exposure of children to digital media by adding concrete hand manipulatives in teaching. The study adds information to the lens of curricular innovations for the post-COVID-19 era.

\section{Conclusion}

This study focused on documenting shifts in pupils' learning progressions when they used manipulative kits and apps on touch-screen devices while learning fractions. The results revealed patterns in pupils' engagement and progression shifts in their learning. These results suggest that various tasks and levels of difficulty may lead the children to refine their comprehension and reshape their perceived concepts to different mathematical ideas resulting in incremental shifts in learning. When the student teachers observed pupils' learning progressions shifting forward and backward, exhibited by variability in children's learning progression scores, this often led to positive shifts between competencies. This productive failure encouraged children to test their selfconstructed concept against multiple scenarios and increase to a complete understanding of the mathematical topic. By conducting an in-depth analysis of individual pupils and documenting the incremental shifts in their developing mathematical ideas, this paper contributes essential insights into what pupils were doing when shifts in their learning progressions occurred. Teachers can use the design features in manipulative mathematics to support and encourage learning shifts. The need to consider the emerging challenges of over-exposure of children to digital media must be a part of the curriculum design. This paper adds information to the lens of curricular innovations for the post-COVID-19 era. With the interconnectedness of the findings, it is proposed that design features in mathematics apps paired with tangible manipulative kits be considered on a large population investigation in primary school mathematics.

\section{Limitations}

The paper presented the interconnectedness of qualitative and quantitative data in a small population. The potential shortcoming in the study is the limited quantitative data on pupils' learning progression and the scores in different competencies under investigation. As to the research design 
requirements, nevertheless, this should not affect the general result of the study.

\section{Data Availability}

The data used are available on request through the e-mail address of Cebu Technological University Educational Research and Resource Center (CTU-ERRC) at errc@ ctu.edu.ph.

\section{Additional Points}

It is proposed that the teaching-learning process and the design feature in mathematics apps paired with manipulative kits be investigated on a large population of primary graders and teachers.

\section{Conflicts of Interest}

The authors declare that they have no conflicts of interest.

\section{References}

[1] K. M. Moser, T. Wei, and D. Brenner, "Remote teaching during COVID-19: implications from a national survey of language educators," System, vol. 97, Article ID 102431, 2021.

[2] UNESCO, "From disruption to recovery," 2022, https://en. unesco.org/covid19/educationresponse.

[3] D. Vargo, L. Zhu, B. Benwell, and Y. Zheng, "Digital technology use during COVID -19 pandemic: a rapid review," Human Behavior and Emerging Technologies, vol. 3, no. 1, pp. 13-24, 2021.

[4] M. Akmal and L. Pritchett, "Learning equity requires more than equality: learning goals and achievement gaps between the rich and the poor in five developing countries," International Journal of Educational Development, vol. 82, Article ID 102350, 2021.

[5] A. J. Baroody, A Guide to Teaching Mathematics in the Primary Grades, Allyn and Bacon, Needham Heights, MA USA, 1989.

[6] A. J. Baroody, "The use of concrete experiences in early childhood mathematics instruction," Advances in Child Development and Behavior, vol. 53, pp. 43-94, 2017.

[7] S. Pirie and T. Kieren, "Growth in mathemcatical understanding: how can we charactirise it and how can we represent it?" Educational Studies in Mathematics, vol. 26, pp. 165-190, 1994.

[8] C. M. Watts, P. S. Moyer-Packenham, S. I. Tucker et al., "An examination of children's learning progression shifts while using touch screen virtual manipulative mathematics apps," Computers in Human Behavior, vol. 64, pp. 814-828, 2016.

[9] S. Pirie and T. E. Kieren, "Beyond metaphor: formalising in mathematical understanding within constructivist environments," For the Learning of Mathematics, vol. 14, no. 1, pp. 39-43, 1994.

[10] L. C. Wilkinson, "Teaching the language of mathematics: what the research tells us teachers need to know and do," The Journal of Mathematical Behavior, vol. 51, pp. 167-174, 2018.

[11] K. J. Carbonneau, S. C. Marley, and J. P. Selig, "A metaanalysis of the efficacy of teaching mathematics with concrete manipulatives," Journal of Educational Psychology, vol. 105, no. 2, pp. 380-400, 2013.
[12] A. Baccaglini-Frank, G. Carotenuto, and N. Sinclair, "Eliciting preschoolers' number abilities using open, multi-touch environments," ZDM, vol. 52, no. 4, pp. 779-791, 2020.

[13] E. D. Doias, The effect of manipulatives on achievement scores in the middle school mathematics class, $\mathrm{PhD}$ Thesis, Lindenwood University, Ann Arbor, MI, USA, 2013.

[14] G. M. Johnson, "Young children at risk of digital disadvantage," in Young Children and Families in the Information Age, K. L. Heider and M. Renck Jalongo, Eds., Springer Netherlands, Dordrecht, Netherlands, pp. 255-275, 2015.

[15] M. A. Scheffelin and C. Seltzer, "Math manipulatives for learning disabilities," Academic Therapy, vol. 9, no. 5, pp. 357-362, 1974.

[16] A. Lafay, H. P. Osana, and M. Valat, "Effects of interventions with manipulatives on immediate learning, maintenance, and transfer in children with mathematics learning disabilities: a systematic review," Education Research International, vol. 2019, Article ID 2142948, 21 pages, 2019.

[17] S. Pirie and K. Tom, "A recursive theory of mathematical understanding," For the Learning of Mathematics, vol. 9, no. 3, pp. 7-11, 1989.

[18] X. Yao, “Unpacking learner's growth in geometric understanding when solving problems in a dynamic geometry environment: coordinating two frames," The Journal of Mathematical Behavior, vol. 60, Article ID 100803, 2020.

[19] H. Gülkılık, H. H. Uğurlu, and N. Yürük, "Examining students' mathematical understanding of geometric transformations using the pirie-kieren model," Educational Sciences: Theory and Practice, vol. 15, no. 6, 2015.

[20] J. W. Creswell and V. L. P. Clark, Designing and Conducting Mixed Methods Research, Sage Publication, Thousand Oaks, California, USA, 2007.

[21] J. W. Creswell, Steps in Conducting a Scholarly Mixed Methods Study, DigitalCommons@University of Nebraska - Lincoln, Lincoln, NE, USA, 2013.

[22] A. Tashakkori and C. Teddlie, SAGE Handbook of Mixed Methods in Social \& Behavioral Research, SAGA Publishing, Thousand Oaks, CA, USA, 2 edition, 2010.

[23] G. Gonzales and R. Gonzales, "Introducing IWB to preservice mathematics teachers: an evaluation using the TPACK framework," Cypriot Journal of Educational Sciences, vol. 16, no. 2, pp. 436-450, 2021.

[24] J. L. M. Wilkins and N. Anderson, "Learning progression toward a measurement concept of fractions," International Journal of STEM Education, vol. 5, no. 1, p. 27, 2018.

[25] P. Howard and B. Perry, "Manipulatives in primary mathematics: implications for learning and teaching," Australian Primary Mathematics Classroom, vol. 2, no. 2, pp. 25-30, 1997.

[26] G. Gonzales, "A mathematical kit for teaching fractions," 2018, https://patents.google.com/patent/PH22017000555Y1/ en.

[27] A. Adesina, R. Stone, F. Batmaz, and I. Jones, "Touch arithmetic: a process-based computer-aided assessment approach for capture of problem solving steps in the context of elementary mathematics," Computers \& Education, vol. 78, pp. 333-343, 2014.

[28] B.-B. Marte, "Key challenges of using video when investigating social practices in education: contextualization, magnification, and representation," International Journal of Research and Method in Education, vol. 40, no. 5, pp. 511-523, 2017.

[29] U. Wilensky and M. S. Walter, “Assessing learning as emergent phenomena: moving constructivist statistics beyond 
the bell-curve," in Research Methods in Mathematics and Science Education Taylor \& Francis, Oxford, UK, 1999.

[30] M. Mendiburo, T. Hasselbring, and G. Biswas, "Teaching fractions with technology: what type of support do students need as they learn to build and interpret visual models of fractions ordering problems?" Journal of Cognitive Education and Psychology, vol. 13, no. 1, pp. 76-87, 2014.

[31] D. H. Clements and J. Sarama, "Learning trajectories in early mathematics-sequences of acquisition and teaching," Encyclopedia of Language and Literacy Development, vol. 7, pp. 1-6, 2009.

[32] N. Duzenli-Gokalp and M. D. Sharma, "A study on addition and subtraction of fractions: the use of Pirie and kieren model and hands-on activities," Procedia-Social and Behavioral Sciences, vol. 2, no. 2, pp. 5168-5171, 2010.

[33] G. King, J. McDougall, D. DeWit et al., "Pathways to children's academic performance and prosocial behaviour: roles of physical health status, environmental, family, and child factors," International Journal of Disability, Development and Education, vol. 52, no. 4, pp. 313-344, 2005.

[34] J. Mcdougall and L. Miller, "Measuring chronic health condition and disability as distinct concepts in national surveys of school-aged children in Canada: a comprehensive review with recommendations based on the ICD-10 and ICF," Disability \& Rehabilitation, vol. 25, no. 16, pp. 922-939, 2003.

[35] S. P. Becker, R. Breaux, R. D. Melissa, N. P. Marsh, S. Emma, and C. N. Cusick, "Remote learning during COVID-19: examining school practices, service continuation, and difficulties for adolescents with and without attention-deficit/ hyperactivity disorder," Journal of Adolescent Health, vol. 67, no. 6, pp. 769-777, 2020.

[36] J. S. Bruner, The Process of Education, Harvard University Press, Cambridge, MA, USA, 1960.

[37] N. Blair, Technology Integration for the New 21st Century Learner, National Association of Elementary School Principals (NAESP), Alexandria, VA, USA, 2012.

[38] C. Hurst and C. Linsell, "Manipulatives and multiplicative thinking," European Journal of STEM Education, vol. 5, no. 1, p. 4,2020 .

[39] R. L. Gerwin, K. Kaliebe, and M. Daigle, "The interplay between digital media use and development," Child and Adolescent Psychiatric Clinics, vol. 27, no. 2, pp. 345-355, 2018. 